\title{
Exercise-Based Cardiac Rehabilitation: Secondary Data Analyses of Mortality and Working Capacity in Germany, 2010-2017
}

\author{
Lars Gabrys ${ }^{1 *} \mathbb{B}$, Johannes Soff ${ }^{2}$, Christian Thiel ${ }^{2}$, Christian Schmidt ${ }^{3}$, Enno Swart $^{4}$ and Dirk Peschke ${ }^{2}$
}

\begin{abstract}
Background: Exercise-based cardiac rehabilitation is safe and implemented in international cardiac rehabilitation guidelines. Evidence for long-term health effects is scarce and rare for health care service research.

Objective: The aim of this study is to evaluate the effectiveness of exercise-based phase III cardiac rehabilitation programs in improving mortality and working capacity outcomes.

Methods: The present analyses used claims data of the German pension fund from 2010 to 2017. Overall, 54,163 patients with coronary heart disease (ICD10 120.-I25.) were included and followed up for exercise-based cardiac rehabilitation participation (mean $4.3 \pm 1.9$ years). All patients were categorized according to participation duration (long: $\geq 90$ days, short: $<90$ days, no). The effectiveness of exercise-based rehabilitation was analyzed by calculating adjusted hazard ratios for mortality and reduced working capacity in relation to program participation.

Results: Of all the cardiac patients, 57.6\% received medical recommendations for exercise-based phase III rehabilitation, and 16.8\% participated in this rehabilitation. In total, 1776 (3.3\%) patients died during the study period, and 3050 (5.5\%) received reduced earning capacity pensions. Mortality risk was nearly doubled for those who did not participate in exercise-based cardiac rehabilitation compared to those who participated for a long duration (HR 1.97, 95\% Cl 1.60-2.43) and 44\% higher compared to a short participation (HR 1.44,95\% Cl 1.03-2.01). Furthermore, the risk of reduced working capacity was higher for those who did not participate compared to those who participated for a short duration (HR 1.24, 95\% Cl 1.00-1.54).

Conclusion: Exercise-based phase III cardiac rehabilitation is independently associated with reduced mortality and reduced loss in working capacity. Strong efforts should be made to increase participation rates to improve cardiac patients care.
\end{abstract}

Keywords: Exercise, Physical activity, Sports, Rehabilitation, Health care, Cardiology, Epidemiology

\section{Key Points}

- Outpatient exercise-based cardiac rehabilitation (phase III) is a cornerstone to induce long-term health behavior change and stabilize health out-

\footnotetext{
*Correspondence: gabrys@fhsmp.de

1 Department of Sport and Prevention, University of Applied

Sciences for Sport and Management Potsdam, Am Luftschiffhafen 1,

14471 Potsdam, Germany

Full list of author information is available at the end of the article
}

comes. Patients who adhere to these programs show lower mortality rates and a better working capacity compared to cardiac patients who do not participate.

- Although exercise-based cardiac rehabilitation is implemented in national and international guidelines, only $16.8 \%$ of cardiac patients are successfully referred to structured rehabilitation programs in Germany.

- Strong efforts should be made to increase participation rates to improve cardiac patients care. Digital 
tools like cardiac telerehabilitation could make exercise-based cardiac rehabilitation more widely accessible and tailored to individual needs.

\section{Introduction}

Coronary heart disease (CHD) or ischemic heart disease is the second leading cause of disability-adjusted life years (DALYs) worldwide. It is the leading cause of DALYs among persons over 50 years of age [1]. In Germany, CHD exhibits a lifetime prevalence of $6.4 \%$ in women and $12.3 \%$ in men, and the prevalence of this condition increases with age [2,3]. In 2019, more than 330,000 deaths in Germany were attributable to cardiovascular diseases [4] and 838,000 hospital admissions due to CHD were documented nationwide [5]. Although CHD incidence rates and cardiovascular mortality have decreased over the last few decades [2], morbidity, reduced physical capacity and physical functioning, and premature death remain high in CHD survivors [6].

The German healthcare system offers inpatient or outpatient rehabilitation care for CHD patients, and the associated costs are covered by social insurance agencies. Depending on the patient's age and working ability, rehabilitation measures must be paid for by statutory health insurances, the German pension fund (DRV), or private health insurances (e.g., for patients who have higherincome levels, are self-employed, or are civil servants). For the majority of the working population, the German pension fund covers rehabilitation costs.

After a cardiac event or elective cardiac surgery, the rehabilitation process within the German healthcare system comprises three sequential rehabilitation stages. The first stage (Phase I) focuses on intensive care and early mobilization within the hospital. The second stage (Phase II) includes a 3-4-week inpatient or outpatient medical rehabilitation program with a focus on improving physical capacity, disease management, quality of life, and return to work [7]. Exercise and sports therapy are major components of Phase II cardiac rehabilitation [8, 9]. There is clear evidence for the prognostic significance of exercise training and cardiorespiratory fitness, which are inversely related to cardiovascular mortality. Further, the antiatherosclerotic, antiischemic, antiarrhythmic, antithrombotic, and psychological mechanisms of regular physical activity and exercise, responsible for the decreased mortality are well known [10]. Exercise-based cardiac rehabilitation is safe and effective, can reduce cardiovascular mortality by $26 \%$ and rehospitalization by $18 \%$, and can also improve both health-related and overall quality of life $[9,11,12]$. To stabilize treatment outcomes and support long-term lifestyle and behavior changes, cardiac patients are encouraged to attend exercise-based outpatient aftercare programs in Phase III rehabilitation (EBRP-III). In these exercise-based group programs, patients should exercise regularly at or near their places of residence to improve health, reduce cardiovascular risk, and prevent the loss of working capacity and early retirement. Typically, EBRP-III is prescribed by a physician (often a general practitioner), should start within three months after Phase II, and should be continued for as long as possible. It involves 1-2 regular group exercise sessions per week, each lasting for at least $60 \mathrm{~min}$ and guided by a rehabilitation trainer under the surveillance of a physician. These rehabilitation trainers and programs must be licensed and listed by either the German Society of Cardiovascular Prevention and Rehabilitation (DGPR) or the German National Paralympic Committee (DBS). A prescription within the scope of the German pension fund typically covers a period of six months. Rehabilitation goals, such as body functioning and participation, are in accordance to the International Classification of Functioning (ICF) [13, 14].

In 2014, 5\% $(\mathrm{N}=46,894)$ of all Phase II rehabilitation measures of the German pension fund were related to CHD (e.g., myocardial infarction). Of these patients, approximately $60 \%$ received prescriptions for EBRPIII [15]. Participation analyses have shown that only a minority (9.7-22.5\%) of CHD patients have actually participated in EBRP-III [16]. Furthermore, little is known as to whether these patients benefit from program participation.

The present paper uses claims data to analyze the effects of EBRP-III on CHD patients in terms of mortality and lost working capacity.

\section{Methods}

\section{Data Basis}

We used claims data of the German pension fund for the present analyses. The Scientific Use File (SUF) "completed rehabilitation measures 2010-2017" (Abgeschlossene Rehabilitationen 2010-2017 [in German]) is available upon request for scientific institutions. The dataset contains person-based data with records on insured persons and their eligible relatives. Included are persons with one of the following characteristics within the observed period (2010-2017): completed rehabilitation, approved pension or belonging to a specific demographic cohort (death before or at the age of 75 or belonging to a certain year of birth). Persons whose applications for rehabilitation or for any pension had finally been denied are excluded. For each rehabilitation, pension, or demographic event, included persons are being observed over an 8-year period, with minor exceptions (e.g. date of death information is available up to 9 years after the first documented event.) The SUF is a complex random 
sample regarding the aforementioned events and comprises a random sample of $20 \%$ of all insured persons $(\mathrm{N} \approx 3.7$ million). We used the given weighting factor to infer from the random sample to the target population. Given that the DRV is the main payer for rehabilitation services for the working population of Germany, the age range of the participants in this dataset is typically between 16 and 66 years. A detailed description of the dataset, including the sampling design, can be found elsewhere $[17,18]$. Due to its longitudinal design (with individual data from 2010 to 2017), the SUF is an appropriate source for the analysis of the effects and time trends of rehabilitation services.

The study adheres to the reporting guidelines of the STROBE Statement for observational studies [19].

\section{Participants and Outcomes}

Out of the complete dataset of 3.7 million insured persons, we only used data with information on medical rehabilitation measures for our analyses. For these approximately 2.2 million patients we defined the following inclusion and exclusion criteria.

\section{Inclusion Criteria}

In the first step, we included rehabilitation patients with a primary diagnosis of CHD or ischemic heart disease (ICD10 I20.-I25.) who had completed medical rehabilitation (Phase II). In the next step, we matched EBRP-III to our study population. Participation had to start within six months after completing Phase II rehabilitation.

\section{Exclusion Criteria}

People who died within a 12-month period after completing Phase II rehabilitation were excluded to avoid selection bias due to the inclusion of severely ill patients. We also excluded persons without regularly completed rehabilitation phase II because of medical problems or premature termination of any other cause.

The time of study entry was determined by the date of the first use of Phase II rehabilitation services, which could have been any date after January 1, 2010. Patients were followed up for mortality or reduced working capacity as primary study outcomes until December 31, 2017. The loss of working capacity was determined by the payment of a reduced earning capacity pension by the DRV. Based on the actual duration of EBRP-III participation, we defined three separate study groups: 1 ) no participation, 2) short participation ( $<90$ days), and 3) long participation ( $\geq 90$ days). A participation duration of 90 days indicated an EBRP-III program participation rate of a minimum of $50 \%$, which was defined as acceptable adherence (long participation).

\section{Covariates}

In our analyses we used a stepwise selection procedure for the selection of covariates. Education level was determined using the available data on the highest level of schooling and/or professional training. Education was categorized as lower secondary or elementary school with or without professional training, higher education entrance qualification with or without professional training, university degree, or no information available.

Subjective medical rehabilitation outcome was determined based on the physician's assessment indicated in the Phase II rehabilitation discharge letter. Patients could rate their rehabilitation outcome as worse, unchanged, or better.

Information regarding sick leave was based on DRV recordings and expressed as days of absence from work within the last 12 months prior to rehabilitation entry. This data was categorized as no days of absence, less than 3 months of absence, 3-6 months of absence, more than 6 months of absence, or not employed.

The number of comorbidities represented the number of documented physician-based diagnoses next to $\mathrm{CHD}$ or ischemic heart disease to represent the degree of multi-morbidity.

\section{Statistical Analyses}

For unadjusted analyses and baseline characteristics, a $\mathrm{Chi}^{2}$ test was applied for associations between sex, education, subjective medical rehabilitation outcome (Phase II), sick leave, age at rehabilitation entry, number of comorbidities, and participation in EBRP-III (3 groups). For adjusted analyses, Cox proportional hazards models were applied to account for potential confounding in the relationship between program participation and mortality or reduced earning capacity, respectively [20]. The exposure variable was program participation, with "long participation" as the reference category.

For sensitivity analyses, we used a shorter period of only six months of minimum survival after completing medical rehabilitation (Phase II).

All analyses were performed using the mentioned weighting factor which is provided within the SUF to account for a disproportional sampling procedure [18]. Furthermore, all analyses were performed with the statistical software package SAS University Edition (SAS Institute, Cary, NC, USA). A p-value $<0.05$ was considered to indicate statistical significance. For the reporting of patient pathways and outcomes within the German rehabilitation system we used a Sankey diagram. Sankey diagrams are a type of flow diagram in which the width of the arrows is proportional to the flow rate. In our case all CHD patients were divided in two groups (participators 
vs. non-participators) and the connections (arrows) show the evolution between different stages of the rehabilitation process.

\section{Results}

After the inclusion and exclusion criteria were applied, 54,163 CHD patients remained in the final dataset. Of those, $57.6 \%$ received medical recommendations for EBRP-III, $16.8 \%$ participated in EBRP-III, and $11.9 \%$ participated for more than 90 days (long participation). Furthermore, 1776 (3.3\%) patients died, and 3050 (5.5\%) received reduced earning capacity pensions during the study period (Fig. 1).

Table 1 shows significant differences in the distribution of demographic characteristics by participation in EBRP-III among CHD patients with the exception for the number of comorbidities. Compared to the average (total), long participation in EBRP-III was more prevalent in women compared to men and older patients were more often adherent to long participation compared to younger patients. Patients with shorter job absence due to sick leave ( $<3$ months) prior to rehabilitation entry and patients with a better subjective rating of their rehabilitation outcome showed slightly higher long participation rates to exercise-based aftercare compared to patients with longer durations of sick leave or unchanged subjective outcome rating.

Table 2 shows the adjusted hazard ratios (HR) for mortality risk as the first primary study outcome. Compared to CHD patients who adhere to EBRP-III for more than 90 days, mortality risk was nearly doubled among CHD patients who did not exercise in structured rehabilitation aftercare programs (HR: 1.97; 95\% CI: $1.60-2.43)$ and $44 \%$ higher compared to short participation. Furthermore, men had a 58\% higher mortality risk compared to women, and mortality risk increased with age and number of comorbidities. Duration of sick leave prior to rehabilitation entry was also associated with higher mortality risk. For unemployed persons, the mortality risk increased by $68 \%$.

Table 3 shows the adjusted HR for reduced working capacity as the second primary study outcome. Short participation in EBRP-III was associated with a $24 \%$ increase in loss of working capacity compared to long participation. Non-participation in EBRP-III was not associated with a significantly increased risk of loss in working capacity. The risk for loss of working capacity was lower for men compared to women, and this risk decreased by $2 \%$ with every additional year of age. Each accompanying disease was associated with an $8 \%$ increased risk for loss of working capacity. Duration of sick leave prior to Phase II rehabilitation entry was also associated with higher risk for loss of working capacity.

All findings remained similar when we used shorter periods of only 6 months of minimum survival after completing medical rehabilitation (Phase II) for sensitivity analyses.

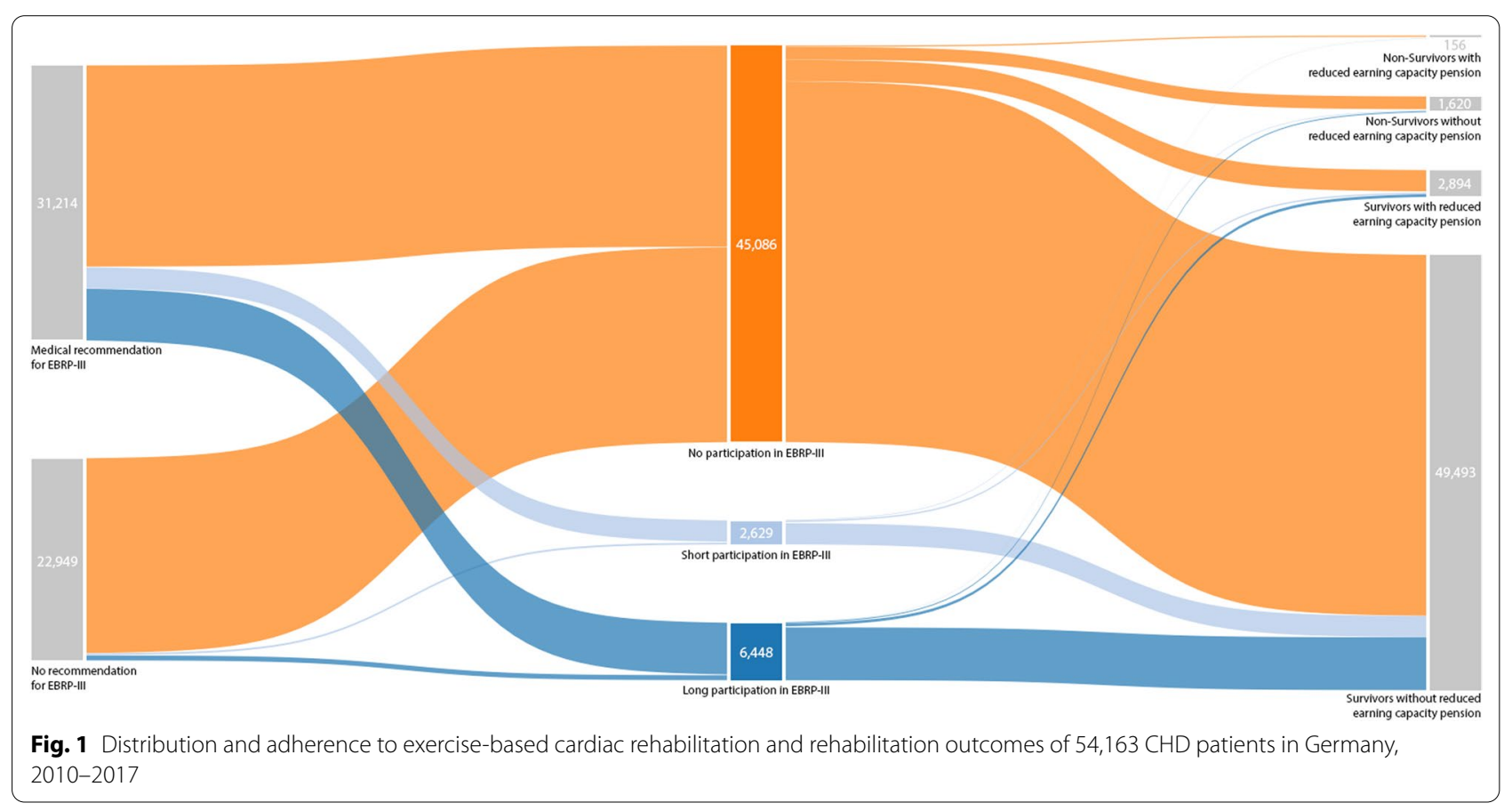


Table 1 Baseline characteristics (at rehabilitation entry) and group comparison regarding EBRP-III ${ }^{\dagger}$ participation of 54,163 CHD* patients in Germany, 2010-2017

\begin{tabular}{|c|c|c|c|c|c|}
\hline & \multirow[t]{2}{*}{ Total } & \multicolumn{3}{|c|}{ EBRP-III participation } & \multirow[t]{2}{*}{ p-value } \\
\hline & & No participation & $\begin{array}{l}\text { Short participation } \\
\text { (<90 days) }\end{array}$ & $\begin{array}{l}\text { Long participation } \\
\text { (>90 days) }\end{array}$ & \\
\hline N (\%) & $54,163(100 \%)$ & $45,086(83.2 \%)$ & $2629(4.9 \%)$ & $6448(11.9 \%)$ & \\
\hline Years under observation (mean \pm SD) & $4.3 \pm 1.8$ & $4.3 \pm 1.9$ & $4.4 \pm 1.8$ & $4.4 \pm 1.8$ & \\
\hline Sex & & & & & $<.0001$ \\
\hline Men & $45,019(83.1 \%)$ & $37,785(83.8 \%)$ & $2149(81.7 \%)$ & $5085(78.9 \%)$ & \\
\hline Women & $9144(16.9 \%)$ & $7301(16.2 \%)$ & $480(18.3 \%)$ & $1363(21.1 \%)$ & \\
\hline Age & & & & & $<.0001$ \\
\hline$<50$ years & $14,478(26.7 \%)$ & $12,353(27.4 \%)$ & $796(30.3 \%)$ & $1329(20.6 \%)$ & \\
\hline $50-54$ years & $13,787(25.5 \%)$ & $11,548(25.6 \%)$ & $716(27.2 \%)$ & $1523(23.6 \%)$ & \\
\hline $55-59$ years & $15,827(29.2 \%)$ & $12,951(28.7 \%)$ & $744(28.3 \%)$ & $2132(33.1 \%)$ & \\
\hline $60-66$ years & $10,071(18.6 \%)$ & $8234(18.3 \%)$ & $373(14.2 \%)$ & $1464(22.7 \%)$ & \\
\hline Comorbidities & & & & & .0904 \\
\hline No comorbidities & $2378(4.4 \%)$ & $1952(4.3 \%)$ & $117(4.5 \%)$ & $309(4.8 \%)$ & \\
\hline 1-2 comorbidities & $14,386(26.6 \%)$ & 11,908 (26.4\%) & $733(27.9 \%)$ & $1745(27.1 \%)$ & \\
\hline Three or more comorbidities & $37,399(69.0 \%)$ & $31,226(69.3 \%)$ & $1779(67.7 \%)$ & $4394(68.1 \%)$ & \\
\hline Education & & & & & $<.0001$ \\
\hline No information & $49,564(91.5 \%)$ & $40,921(90.8 \%)$ & $2520(95.9 \%)$ & $6123(95.0 \%)$ & \\
\hline Lower education & $3964(7.3 \%)$ & $3606(8.0 \%)$ & $94(3.6 \%)$ & $264(4.1 \%)$ & \\
\hline Higher education & $493(0.9 \%)$ & $451(1.0 \%)$ & $7(0.3 \%)$ & $35(0.5 \%)$ & \\
\hline University degree & $142(0.3 \%)$ & $108(0.2 \%)$ & $8(0.3 \%)$ & $26(0.4 \%)$ & \\
\hline Sick leave prior to rehabilitation entry & & & & & $<.0001$ \\
\hline Not employed & $2059(3.8 \%)$ & $1792(4.0 \%)$ & $69(2.6 \%)$ & $198(3.1 \%)$ & \\
\hline$>6$ months & $2899(5.4 \%)$ & $2513(5.6 \%)$ & $128(4.9 \%)$ & $258(4.0 \%)$ & \\
\hline $3-6$ months & $3477(6.4 \%)$ & $2946(6.5 \%)$ & $161(6.1 \%)$ & $370(5.7 \%)$ & \\
\hline$<3$ months & $39,529(73.0 \%)$ & $32,502(72.1 \%)$ & $2038(77.5 \%)$ & $4989(77.4 \%)$ & \\
\hline No & $6199(11.4 \%)$ & $5333(11.8 \%)$ & $233(8.9 \%)$ & $633(9.8 \%)$ & \\
\hline Subjective rehabilitation outcome (Phase II) & & & & & .0012 \\
\hline No information & 1922 (3.5\%) & 1578 (3.5\%) & 99 (3.8\%) & $245(3.8 \%)$ & \\
\hline Worse & 38 (0.1\%) & $32(0.1 \%)$ & $3(0.1 \%)$ & $3(0.0 \%)$ & \\
\hline Unchanged & 7274 (13.4\%) & 6185 (13.7\%) & $326(12.4 \%)$ & 763 (11.8\%) & \\
\hline Better & $44,929(83.0 \%)$ & 37,291 (82.7\%) & 2201 (83.7\%) & 5437 (84.3\%) & \\
\hline
\end{tabular}

$\mathrm{p}$-value: $\mathrm{Chi}^{2}$-Test was used to test for group differences

${ }^{*}$ CHD: Coronary Heart Disease

${ }^{\dagger}$ EBRP-III: Exercise-based rehabilitation phase III

\section{Discussion}

The focus of the present paper is on the effectiveness of exercise-based cardiac rehabilitation in EBRP-III. Exercise-based cardiac rehabilitation is strongly recommended in national and international guidelines, and its costs are covered by the German pension fund [8, 9]. We used claims data to evaluate the effectiveness of real-world healthcare services. To the best of our knowledge, this is a rarely used study design to address this issue in exercise rehabilitation and the first study of its kind using German data. First of all, our data show an overall low participation rate. Only $16.8 \%$ of all CHD patients participated in structured EBRP-III programs and only $11.9 \%$ did adhere to these programs for more than 90 days. Second, we see age and sex differences in long-term exercise participation as well as the influence of sick leave prior to rehabilitation entry. Furthermore, our data indicate a beneficial effect of EBRP-III outpatient aftercare programs on CHD patients' rates of mortality and lost working capacity. This effect was larger for mortality and increased with longer program participation. Patients who did not participate in structured cardiac rehabilitation programs had nearly twice the risk of death of patients who regularly exercised in 
Table 2 Association between exercise-based rehabilitation participation (Phase III) and mortality among 54,106 CHD* patients in Germany, 2010-2017

\begin{tabular}{|c|c|c|c|c|}
\hline & Cases & HR & $95 \% \mathrm{Cl}$ & $p$ \\
\hline \multicolumn{5}{|c|}{$\begin{array}{l}\text { Exercise-based rehabilitation (Phase } \\
\text { III) }\end{array}$} \\
\hline No participation & 45,033 & 1.97 & $1.60-2.43$ & $<.0001$ \\
\hline Short participation ( $<90$ days) & 2627 & 1.44 & $1.03-2.01$ & 0.034 \\
\hline Long participation ( $\geq 90$ days) & 6446 & Ref. & & \\
\hline \multicolumn{5}{|l|}{ Sex } \\
\hline Men & 44,977 & 1.58 & $1.35-1.85$ & $<.0001$ \\
\hline Women & 9129 & Ref. & & \\
\hline \multicolumn{5}{|l|}{ Age } \\
\hline $\begin{array}{l}\text { Age upon rehabilitation entry } \\
\text { (Phase II) }\end{array}$ & 54,106 & 1.05 & $1.04-1.06$ & $<.0001$ \\
\hline \multicolumn{5}{|l|}{ Comorbidities } \\
\hline Number of comorbidities & 54,106 & 1.07 & $1.02-1.13$ & 0.005 \\
\hline \multicolumn{5}{|l|}{ Education } \\
\hline No information & 49,514 & 1.50 & $0.59-3.79$ & 0.391 \\
\hline Lower education & 3957 & 2.25 & $0.88-5.72$ & 0.089 \\
\hline Higher education & 493 & 1.35 & $0.47-3.90$ & 0.584 \\
\hline University degree & 142 & Ref. & & \\
\hline \multicolumn{5}{|c|}{ Sick leave prior to rehabilitation entry } \\
\hline Not employed & 2053 & 1.68 & $1.31-2.15$ & $<.0001$ \\
\hline$>6$ months & 2897 & 1.92 & $1.54-2.39$ & $<.0001$ \\
\hline $3-6$ months & 3476 & 1.29 & $1.02-1.63$ & 0.034 \\
\hline$<3$ months & 39,490 & 0.89 & $0.76-1.05$ & 0.149 \\
\hline No & 6190 & Ref. & & \\
\hline \multicolumn{5}{|l|}{$\begin{array}{l}\text { Subjective rehabilitation outcome } \\
\text { (Phase II) }\end{array}$} \\
\hline No information & 1918 & 0.81 & $0.60-1.10$ & 0.163 \\
\hline Worse & 38 & 2.33 & $0.68-8.08$ & 0.181 \\
\hline Unchanged & 7266 & 1.10 & $0.96-1.27$ & 0.167 \\
\hline Better & 44,884 & Ref. & & \\
\hline
\end{tabular}

$p$-values $<.05$ indicate statistical significance (bold)

${ }^{*} \mathrm{CHD}$ : Coronary Heart Disease

such programs (HR 1.97, 95\% CI 1.60-2.43). A recent study that used a similar approach found similar effects with $68 \%$ reduction in mortality risk for patients with atrial fibrillation (AF) and exercise-based cardiac rehabilitation compared to AF patients with no exercisebased cardiac rehabilitation [21].

One potential reason why we do not see this strong effect in our data for working capacity and actually only for short-term EBRP-III participation (HR 1.24, 95\% CI $1.00-1.54)$ may be that mortality is a competing outcome in the non-participating group. Another explanation for that finding could be that CHD is known to be an age-related disease and patients become retired instead of receiving reduced earning capacity pension. Based on our findings and the existing evidence
Table 3 Association between exercise-based rehabilitation participation (Phase III) and reduced working capacity among 54,163 CHD* patients in Germany, 2010-2017

\begin{tabular}{|c|c|c|c|c|}
\hline & Cases & HR & $95 \% \mathrm{Cl}$ & $p$ \\
\hline \multicolumn{5}{|c|}{$\begin{array}{l}\text { Exercise-based rehabilitation (Phase } \\
\text { III) }\end{array}$} \\
\hline No participation & 45,086 & 1.10 & $0.96-1.26$ & 0.156 \\
\hline Short participation (<90 days) & 2629 & 1.24 & $1.00-1.54$ & 0.049 \\
\hline Long participation ( $\geq 90$ days) & 6448 & Ref. & & \\
\hline \multicolumn{5}{|l|}{ Sex } \\
\hline Men & 45,019 & 0.67 & $0.61-0.74$ & $<.0001$ \\
\hline Women & 9144 & Ref. & & \\
\hline \multicolumn{5}{|l|}{ Age } \\
\hline $\begin{array}{l}\text { Age upon rehabilitation } \\
\text { entry (Phase II) }\end{array}$ & 54,163 & 0.98 & $0.97-0.99$ & $<.0001$ \\
\hline \multicolumn{5}{|l|}{ Comorbidities } \\
\hline Number of comorbidities & 54,163 & 1.08 & $1.03-1.21$ & 0.0003 \\
\hline \multicolumn{5}{|l|}{ Education } \\
\hline No information & 49,564 & 1.20 & $0.50-2.90$ & 0.680 \\
\hline Lower education & 3964 & 2.02 & $0.83-4.89$ & 0.120 \\
\hline Higher education & 493 & 0.84 & $0.30-2.31$ & 0.731 \\
\hline University degree & 142 & Ref. & & \\
\hline \multicolumn{5}{|c|}{ Sick leave prior to rehabilitation entry } \\
\hline Not employed & 2059 & 0.84 & $0.65-1.09$ & 0.189 \\
\hline$>6$ months & 2899 & 2.57 & $2.15-3.07$ & $<.0001$ \\
\hline $3-6$ months & 3477 & 2.12 & $1.77-2.53$ & $<.0001$ \\
\hline$<3$ months & 39,529 & 1.01 & $0.88-1.16$ & 0.903 \\
\hline No & 6199 & Ref. & & \\
\hline \multicolumn{5}{|l|}{$\begin{array}{l}\text { Subjective rehabilitation outcome } \\
\text { (Phase II) }\end{array}$} \\
\hline No information & 1922 & 1.05 & $0.85-1.30$ & 0.658 \\
\hline Worse & 38 & 0.89 & $0.18-4.43$ & 0.891 \\
\hline Unchanged & 7274 & 1.11 & $0.99-1.24$ & 0.074 \\
\hline Better & 44,929 & Ref. & & \\
\hline
\end{tabular}

$p$-values $<.05$ indicate statistical significance (bold)

${ }^{*} \mathrm{CHD}$ : Coronary Heart Disease

for the effectiveness of physical activity in cardiac prevention and rehabilitation, we conclude that an EBRP-III prescription rate of only $57.6 \%$ is not sufficiently high to achieve rehabilitation goals. A previous study already revealed decreasing EBRP-III prescription rates and an overall low participation rate in Germany [16]. Given that guidelines recommend physical activity and (supervised) exercise training for nearly all cardiac patients, EBRP-III prescription appears to be the key component of EBRP-III participation [9]. The vast majority of patients who participated in EBRP-III had received prescriptions, and only a minority had not. It is unclear and undetectable in our data whether all individuals who wanted to become physically active through EBRP-III programs actually had the 
opportunity to do so. This seems crucial, since representative data for Germany show that only $39 \%$ of persons with CHD meet the WHO recommendations for aerobic physical activity [22].

Given that the presence of a medical doctor is compulsory for EBRP-III programs in Germany, more and more EBRP-III providers have had difficulty finding physicians to supervise their outpatient cardiac rehabilitation groups [23]. This is particularly more evident in more rural areas of Germany. A study of MecklenburgWestern Pomerania showed that the overall number of outpatient rehabilitation sport programs in this area was small, and nearly $50 \%$ of the population in this area must travel for more than $60 \mathrm{~min}$ to attend one of these programs [24]. The limited availability of EBRP-III programs for cardiac patients led to the development of a position statement by a working group of the German Cardiac Society (DGK), in cooperation with the German Society for Prevention and Rehabilitation of Cardiovascular Diseases (DGPR). Therein, the authors state that physician attendance is not necessary in a so-called "standard cardiac rehab group" and that such groups should be supervised by a qualified non-physician exercise therapist [23]. This regulatory change in program requirements could improve the availability of EBRP-III and thus lead to better rehabilitation outcomes for cardiac patients in Germany.

Another promising approach to improve adherence rates could be the development and implementation of digital tools to make exercise-based cardiac rehabilitation more widely accessible and tailored to individual needs [25]. The European Association of Preventive Cardiology states that mobile technologies like cardiac telerehabilitation can improve cardiac care in rehabilitation phase II and III and lead to reduced mortality and morbidity and improved quality of life. Such approaches are particularly valuable in times of the current COVID-19 pandemic which has led to closure of many cardiac rehabilitation centers [26].

\section{Strengths and Limitations}

The strengths of this study are its large sample size and a relatively unbiased set of secondary claims data. The data concerning the primary study outcomes (death and loss of working capacity) are robust, as they are linked to the official federal death statistic and the payment of a permanent reduced earning capacity pension, respectively. One major limitation of the study is that the dataset comprises only persons whose rehabilitation costs were covered by the German pension fund. This comprises the majority of the working population (usually $\leq 66$ years of age), with the exception of civil servants and self-employed persons. Therefore, our results are only generalizable to this particular population. It would be interesting if this also applies to the older (non-working) population. Another limitation of this study is that we have no information regarding the frequency of actual program participation.

\section{Conclusion}

Our data indicate a beneficial effect of regular exercise training in EBRP-III on mortality and working capacity of cardiovascular patients in Germany. Given that overall EBRP-III program participation remains low in this population, our results strengthen the case for making better use of existing exercise-based rehabilitation programs and adapting current program requirements.

\section{Abbreviations}

CHD: Coronary heart disease; Cl: Confidence interval; DALYs: Disability adjusted life years; DGK: German Cardiac Society; DGPR: German Society for Prevention and Rehabilitation of Cardiovascular Diseases; DRV: German pension fund; EBRP-III: Exercise-based rehabilitation phase III; HR: Hazard ratio; ICF: International classification of functioning; SUF: Scientific use file; WHO: World Health Organization.

\section{Acknowledgements}

Not applicable.

\section{Authors' contributions}

LG and DP contributed to the conception and design of this work. JS and CS contributed to the data analysis. LG drafted the manuscript. CT, ES, and DP critically revised the manuscript. All authors read and approved the final manuscript.

\section{Funding}

This research received no specific grant from any funding agency in the public, commercial, or not-for-profit sector. Open Access funding enabled and organized by Project DEAL.

\section{Availability of data and materials}

The dataset analyzed in this study was kindly provided upon request by the German pension fund (DRV).

\section{Declarations}

Ethical approval and consent to participate

Not applicable.

Consent for publication

Not applicable.

\section{Competing interests}

Lars Gabrys, Johannes Soff, Christian Thiel, Christian Schmidt, Enno Swart and Dirk Peschke declare that they have no potential conflict of interests that might be relevant to this manuscript.

\section{Author details}

${ }^{1}$ Department of Sport and Prevention, University of Applied Sciences for Sport and Management Potsdam, Am Luftschiffhafen 1, 14471 Potsdam, Germany.

${ }^{2}$ Department of Applied Health Sciences, University of Applied Sciences for Health, Bochum, Germany. ${ }^{3}$ Department of Epidemiology and Health Monitoring, Robert Koch Institute, Berlin, Germany. ${ }^{4}$ Institute for Social 
Medicine and Health System Research, Otto Von Guericke University Magdeburg, Magdeburg, Germany.

Received: 17 August 2021 Accepted: 14 November 2021

Published online: 04 December 2021

\section{References}

1. Vos T, Lim SS, Abbafati C, Abbas KM, Abbasi M, Abbasifard M, et al. Global burden of 369 diseases and injuries in 204 countries and territories, 1990-2019: a systematic analysis for the Global Burden of Disease Study 2019. Lancet. 2020;396(10258):1204-22.

2. Busch MA, Kuhnert R. 12-Month prevalence of coronary heart disease in Germany. J Health Monit. 2017;2(1):58-63.

3. Gößwald A, Schienkiewitz A, Nowossadeck E, Busch M. Prevalence of myocardial infarction and coronary heart disease in adults aged 40-79 years in Germany: results of the German Health Interview and Examination Survey for Adults (DEGS1). Bundesgesundheitsbl. 2013;56(5-6):650-5.

4. Federal Statistical Office (Germany). Cause of deaths statistics. www.desta tis.de. 2019.

5. Zapf A, Bestehorn K. Mortality and morbidity of heart diseases - an overview [in German]. In: Deutscher Herzbericht Deutsche Herzstiftung (ed.) 2019

6. Jeschke E, Baberg H, Dirschedl P, Heyde K, Levenson B, Malzahn J, et al. Complication rates and secondary interventions after coronary procedures in clinical routine: 1-year follow-up based on routine data of a German health insurance company. Dtsch Med Wochenschr. 2013;138(12):570-5.

7. EACPR Committee for Science Guidelines, Corrà U, Piepoli MF, Carré F, Heuschmann P, Hoffmann U, et al. Secondary prevention through cardiac rehabilitation: physical activity counselling and exercise training: key components of the position paper from the Cardiac Rehabilitation Section of the European Association of Cardiovascular Prevention and Rehabilitation. Eur Heart J. 2010;31(16):1967-74.

8. S3-Leitlinie zur kardiologischen Rehabilitation (LL-KardReha) im deutschsprachigen Raum Europas. Deutschland, Österreich, Schweiz (D-A-CH). Version 10 (10122020). 2020.

9. Pelliccia A, Sharma S, Gati S, Bäck M, Börjesson M, Caselli S, et al. 2020 ESC Guidelines on sports cardiology and exercise in patients with cardiovascular disease: the Task Force on sports cardiology and exercise in patients with cardiovascular disease of the European Society of Cardiology (ESC). Eur Heart J. 2021;42(1):17-96.

10. Franklin BA, Lavie CJ, Squires RW, Milani RV, editors. Exercise-based cardiac rehabilitation and improvements in cardiorespiratory fitness: implications regarding patient benefit. Mayo Clinic Proc. 2013; 88(5):431-7.

11. Suaya JA, Shepard DS, Normand S-LT, Ades PA, Prottas J, Stason WB. Use of cardiac rehabilitation by Medicare beneficiaries after myocardial infarction or coronary bypass surgery. Circulation. 2007;116(15):1653-62.

12. Anderson L, Oldridge N, Thompson DR, Zwisler A-D, Rees K, Martin N, et al. Exercise-based cardiac rehabilitation for coronary heart disease: cochrane systematic review and meta-analysis. J Am Coll Cardiol. 2016;67(1):1-12.

13. Bundesarbeitsgemeinschaft für Rehabilitation (BAR). Rahmenvereinbarung über den Rehabilitationssport und das Funktionstraining. 2011.

14. World Health Organization (WHO). The International Classification of Functioning, Disability and Health (ICF). Geneva: WHO; 2001.

15. Deutsche Rentenversicherung. Reha-Bericht 2015. Die medizinische und berufliche Rehabilitation der Rentenversicherung im Licht der Statistik. 2015.

16. Gabrys L, Schmidt C. Prescription and utilization of sports therapy programs following cardiac rehabilitation 2006-2013. Rehabilitation. 2019;59(1):42-7.

17. Nimptsch U, Bestmann A, Erhardt M, Dudey S, Marx Y, Saam J, et al. Zugang zu Routinedaten. In: Swart E, Ihle P, Grothe H, Matusiewicz D, editors., et al., Routinedaten im Gesundheitswesen. 2nd ed. CH-Bern: Huber; 2014. p. 270-90.

18. Forschungsdatenzentrum der Rentenversicherung (FDZ-RV). Scientific Use File. Abgeschlossene Rehabilitationen 2010-2017 im Versicherungsverlauf (SUFRSDLV17B). Berlin: DRV Bund; 2020.
19. Von Elm E, Altman DG, Egger M, Pocock SJ, Gøtzsche PC, Vandenbroucke JP. The Strengthening the Reporting of Observational Studies in Epidemiology (STROBE) statement: guidelines for reporting observational studies. Bull World Health Organ. 2007;85:867-72.

20. Cox DR. Regression models and life-tables. J R Stat Soc Ser B (Methodol). 1972;34(2):187-202.

21. Buckley BJ, Harrison SL, Fazio-Eynullayeva E, Underhill P, Lane DA, Thijssen DH, et al. Exercise-based cardiac rehabilitation and all-cause mortality among patients with atrial fibrillation. J Am Heart Assoc. 2021;10:e020804

22. Sudeck G, Geidl W, Abu-Omar K, Finger JD, Krauß I, Pfeifer K. Do adults with non-communicable diseases meet the German physical activity recommendations? German J Exerc Sport Res. 2021;51(2):183-93.

23. Wienbergen H, Schwaab B, Bjarnason-Wehrens B, Guha M, Laszlo R, Burgstahler C, et al. Physician support for outpatient cardiac rehabilitation groups [in German]. Der Kardiologe. 2020:1-8.

24. Behrens K, Lübke J, Stoll R, Weippert M, Klinger R. GesundheitssportIntegrativer Bestandteil der Gesundheitsversorgung. Dtsch Arztebl. 2015;112:A820-2.

25. Pandey AC, Golbus JR, Topol EJ. Cardiac rehabilitation in the digital era. Lancet. 2021;398(10294):16.

26. Scherrenberg M, Wilhelm M, Hansen D, Völler $H$, Cornelissen V, Frederix I, et al. The future is now: a call for action for cardiac telerehabilitation in the COVID-19 pandemic from the secondary prevention and rehabilitation section of the European Association of Preventive Cardiology. Eur J Prev Cardiol. 2021;28(5):524-40.

\section{Publisher's Note}

Springer Nature remains neutral with regard to jurisdictional claims in published maps and institutional affiliations.

\section{Submit your manuscript to a SpringerOpen ${ }^{\circ}$ journal and benefit from:}

- Convenient online submission

- Rigorous peer review

- Open access: articles freely available online

- High visibility within the field

- Retaining the copyright to your article

Submit your next manuscript at $\boldsymbol{\nabla}$ springeropen.com 